\title{
Assessment of Statistical Methods for Water Quality Monitoring in Maryland's Tidal Waterways
}

\author{
REU Site: Interdisciplinary Program in High Performance Computing
}

\author{
Rosemary K. Le ${ }^{1}$, Christopher V. Rackauckas ${ }^{2}$, Anne S. Ross ${ }^{3}$, Nehemias Ulloa ${ }^{4}$ \\ ${ }^{1}$ Department of Applied Mathematics, Brown University \\ ${ }^{2}$ Department of Mathematics, Oberlin College \\ ${ }^{3}$ Department of Computer Science, Department of Statistics, Colorado State University \\ ${ }^{4}$ Department of Mathematics, California State University, Bakersfield
}

\begin{abstract}
The Chesapeake Bay and its surrounding tributaries are home to over 3,600 species of plants and animals. In order to assess the health of the region, the Maryland Department of Natural Resources (DNR) monitors various parameters, such as dissolved oxygen, with monitoring stations located throughout the tidal waterways. Utilizing data provided by DNR, we assessed the waterways for areas of water quality concern. We analyzed the percentage of the readings taken for each parameter that failed to meet the threshold values and used the Wilcoxon Signed-Rank Test to determine the statuses of the stations. In order to assess the applicability of the Wilcoxon Test given the positive skew in the data, a simulation was performed. This simulation demonstrated that log-transforming the data prior to performing the Wilcoxon Test was not enough to reduce the Type I Error to reasonable levels. Thus, our team developed a relative ranking using a set of multiple comparison methods: a version of the Tukey Test on variance-transformed proportions, the Bonferroni adjustment method, a Bayesian method, and the Benjamini-Hochberg rejection method. From the ranking results we identified when each ranking technique is most applicable to our data.
\end{abstract}

Key Words: Chesapeake Bay, Water quality monitoring, Wilcoxon signed-rank test, True Type I Error estimation, Benjamini-Hochberg method

\section{Introduction}

The Chesapeake Bay and its surrounding waterways provide a habitat for over 3,600 species of plants and animals [8]. It is a valuable resource, both recreationally and commercially, to those who live in the basin [5]. DNR operates 35 continuous monitoring stations [3]. Three of these stations take readings at multiple depths for a total of 38 stations of interest. All of the stations take readings every 10 to 20 minutes, with the majority taking readings every 15 minutes. Various parameters such as water clarity, dissolved oxygen, $\mathrm{pH}$, and chlorophyll are used to help determine the health of the water. Past analyses of this data have been used to determine trends in different regions of the tidal waterways as well as aid in assessing the success of DNR funded projects.

Four parameters are of particular importance in water quality monitoring: dissolved oxygen, chlorophyll, $\mathrm{pH}$, and turbidity. Chlorophyll is the measure by which algae levels are evaluated. Density of chlorophyll in the water is measured in $\mu \mathrm{g} / \mathrm{L}$. An increase in algae 


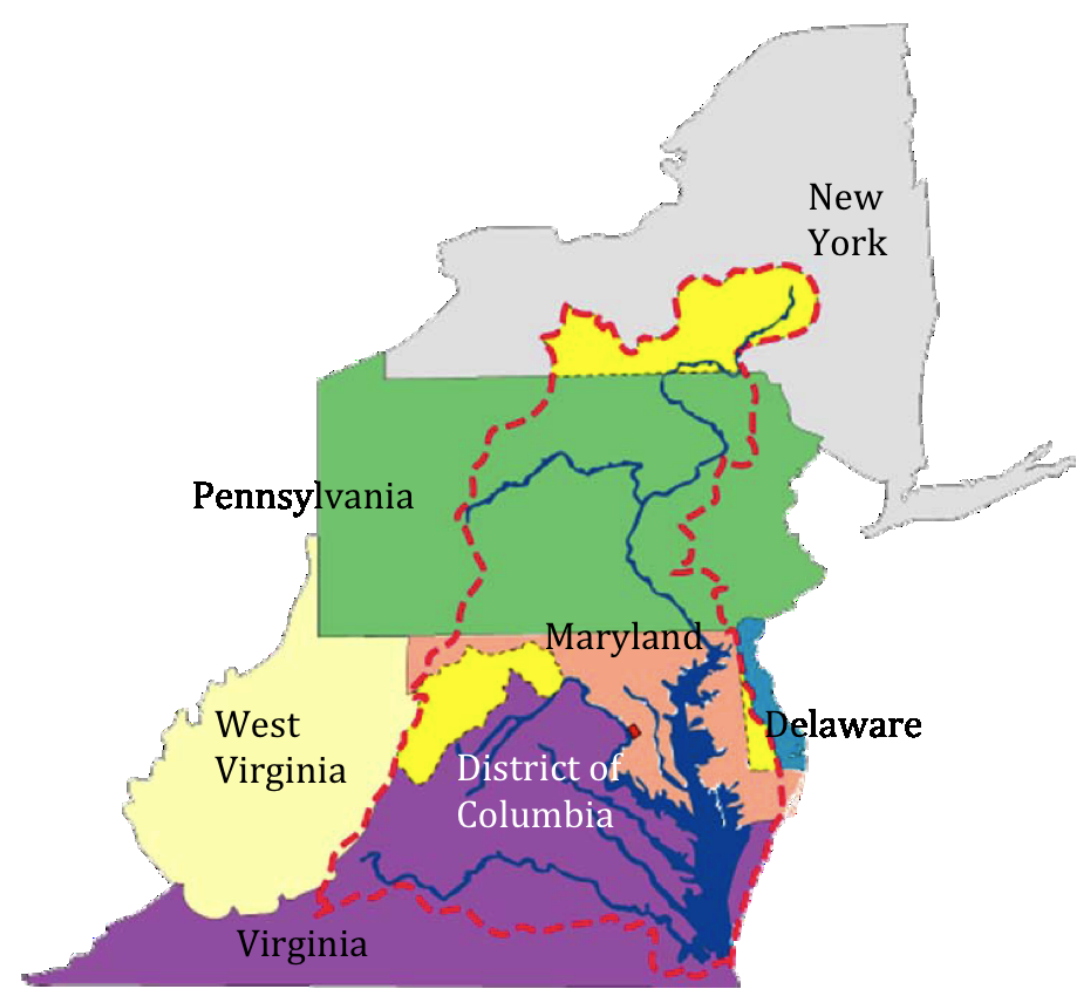

Figure 1.1: The Chesapeake Bay and its tributaries are located on the East Coast, spanning six states (MD, VA, WV, PA, NY, DE) and Washington DC and emptying into the Atlantic Ocean. Image used with permission [3].

levels corresponds to a decrease in water clarity and has a negative impact on dissolved oxygen levels as the algae decomposes. Turbidity is an important measurement of water clarity, the latter being necessary for light to reach submerged aquatic vegetation (SAV) and promote growth. Turbidity is measured in Nephelometric Turbidity Units (NTU) which measures the extent to which a focused light beam scatters in the medium. When analyzing the measurements of chlorophyll and turbidity, larger numbers correspond to less healthy water. Conversely, when considering dissolved oxygen concentrations, higher readings are preferable. While a reading of $5 \mathrm{mg} / \mathrm{L}$ is widely considered a failure threshold, a threshold of $3 \mathrm{mg} / \mathrm{L}$ is often used to test for waters that are severely oxygen-deficient [9].

Summer is a time of particular interest for analyzing these parameters. When evaluating the concentration of dissolved oxygen, the time frame considered is June through September. Chlorophyll and turbidity are evaluated from April through September, the growing season for aquatic vegetation. High levels of chlorophyll and turbidity can have the most detrimental effect on the ecosystem during these months. Lastly, $\mathrm{pH}$, a measure of the acidity of water, is also monitored during these months. This is due to the fact that extreme $\mathrm{pH}$ levels are detrimental to aquatic wildlife [3].

Our project focused on the four parameters listed above. The failure threshold(s) of each parameter and its time frame of greatest interest are summarized in Table 1.1. 
Table 1.1: Failure threshold and time frame of interest.

\begin{tabular}{lll}
\hline Parameter & Failure Threshold & Time Frame \\
\hline Dissolved Oxygen (severe) & $<3 \mathrm{mg} / \mathrm{L}$ & June to September \\
\hline Dissolved Oxygen & $<5 \mathrm{mg} / \mathrm{L}$ & June to September \\
\hline Turbidity & $>7 \mathrm{NTU}$ & April to September \\
\hline Chlorophyll & $>30 \mu \mathrm{g} / \mathrm{L}$ & April to September \\
\hline $\mathrm{pH}$ & $<5.5$ or $>8.3$ & April to September \\
\hline
\end{tabular}

In this paper, we begin by attempting to assess the station performances using the method outlined by DNR for the long-term monitoring stations [4]. This method uses the Wilcoxon Signed-Rank Test, a non-parameteric test which assumes that the distribution from which the data are taken is symmetric. However, the data for some parameters displayed significant asymmetry. To assess the impact of these violations, we simulated the performance of the Wilcoxon Signed-Rank Test on a skewed distribution. This simulation showed that even the standard techniques of log-transforming were not enough to bring the Type I Error rate of the Wilcoxon Signed-Rank test on such skewed data to reasonable levels. From these results we conclude that the methods employed by DNR for long-term monitoring stations do not extend to the continuous monitoring stations. Thus, we investigated relative ranking system which ranked stations with regard to their performance using multiple ranking techniques: a version of the Tukey Test on variance-transformed proportions, the Bonferroni adjustment method, a Bayesian method, and the Benjamini-Hochberg rejection method. From the ranking results we identified when each ranking technique is most applicable to our data.

This paper is organized as follows. Section 2 outlines the statistical methodologies used in the assessment along with a brief description of each method. Section 3 shows the results of the methods. We conclude the report with final remarks in Section 4. 


\section{Methodologies}

\subsection{Percent Failure and Classification of Stations}

We define percent failure as the number of readings that did not meet the DNR-provided threshold divided by the total number of readings multiplied by 100 . For each station, we determine the percent failure in the appropriate timespan for each parameter: dissolved oxygen, chlorophyll, turbidity and $\mathrm{pH}$. We then proceed to use statistical tests that provide more complex insights that allow us to make more statistically sound conclusions.

One such test is the Wilcoxon's Signed-Rank Test which is a non-parametric test used to compare the median of the station's data for a given parameter against the threshold value. The test assumes that the probability distribution from which the data is taken is symmetric. Let $\boldsymbol{x}=\left(x_{1}, x_{2}, \ldots, x_{m}\right)$ be the data vector and thresh be the threshold. The test statistic is given by

$$
S=\mid \sum_{i=1}^{m}\left[R_{i} \cdot \operatorname{sign}\left(x_{i}-\text { thresh }\right)\right],
$$

where $R_{i}$ is the rank of $\mid x_{i}$-thresh $\mid$ in ascending order and the sign function is defined as

$$
\operatorname{sign}(x)= \begin{cases}1 & \text { if } x>0 \\ 0 & \text { if } x=0 \\ -1 & \text { if } x<0\end{cases}
$$

The test rejects the null hypothesis that the median of the data is equal to the threshold if $S$ is sufficiently large. For the purposes of our study, the Wilcoxon Signed-Rank test was used to test the hypothesis:

$$
\begin{aligned}
& H_{0}: \operatorname{median}(\boldsymbol{x})=\text { thresh, } \\
& H_{A}: \operatorname{median}(\boldsymbol{x}) \neq \text { thresh } .
\end{aligned}
$$

The station statuses were defined as "Good" or "Bad" if the Wilcoxon Test rejected the null hypothesis, depending upon if the station's median for that parameter fell on the "unhealthy" or "healthy" side of the threshold value. The station was assigned "Borderline" if the null hypothesis could not be rejected. Our tests were conducted with $\alpha=0.01$. In order to ensure the familywise Type I Error was $\alpha$, we utilized the Benjamini-Hochberg rejection method. This method ranks the p-values in ascending order and rejects the null hypotheses corresponding to the lowest p-values until the cumulative sum of the rejected p-values is equal to $\alpha$. Intuitively, this method rejects the null hypothesis of the tests where the null hypothesis is most likely to be false, that is the tests that have the lowest p-values, until the cumulative p-value is the chosen $\alpha$.

In addition to the symmetry of the underlying distribution, another important assumption for the Wilcoxon Signed-Rank Test is that the observations are independent. In particular, if the data collected over time are autocorrelated, certain properties of the test statistics are in jeopardy. In fact, the Type I error of the Wilcoxon Signed-Rank Test obtained from 


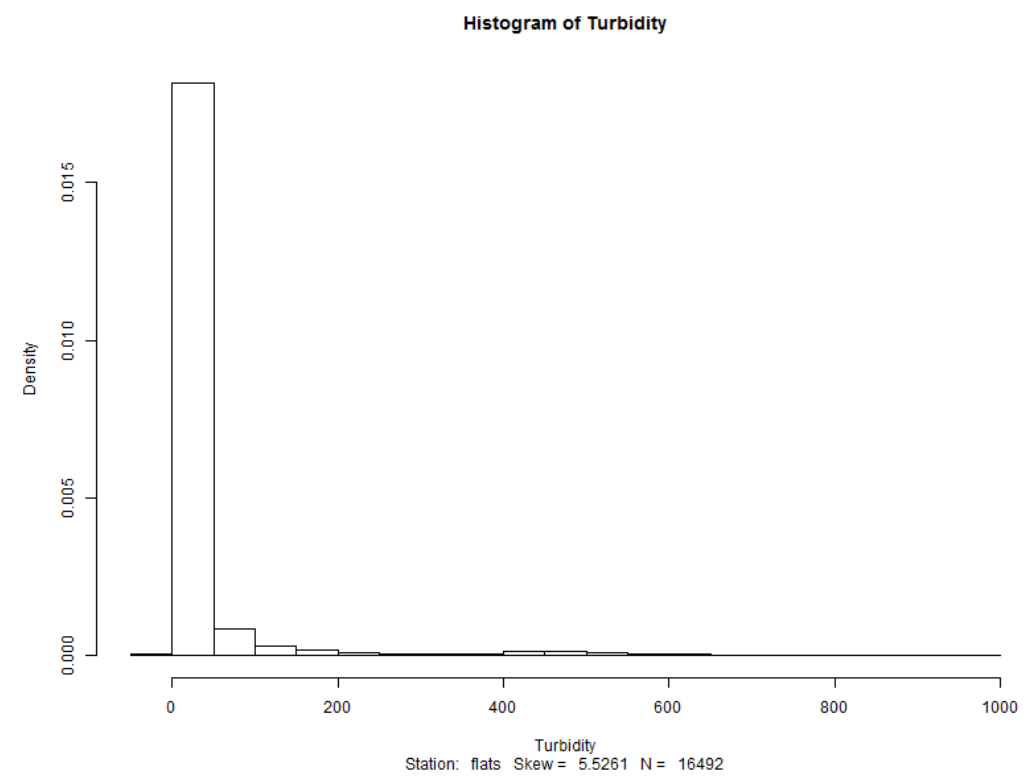

Figure 2.1: Turbidity readings from Flats station is an example of skewness in the data.

autocorrelated data may not be distribution free as is the case for many non-parametric procedures. Similarly, the seasonal fluctuations of the continuous monitoring data also present difficulties. One approach for dealing with seasonality is to construct an overall statistical test based on comparisons within each season. This will also facilitate the threshold value changes from one season to the other. The sensitivity of the Wilcoxon Signed-Rank Test to the departure from these assumptions can be evaluated using simulation studies. As an illustration, we investigate the symmetry assumption and its impact on the performance of the Wilcoxon Signed-Rank Test. Results of this simulation study are presented in the next section.

\subsection{Simulation}

The Wilcoxon Signed-Rank Test is implemented under the assumption that the distribution from which the samples are drawn is symmetric. However, as seen in Figure 2.1, some stations clearly display a positive skew. Thus we decided to run a simulation to assess the impact of the data's skew on the Type I Error rate for the Wilcoxon Signed-Rank Test. For the purposes of our study, we used sample data $\left(x_{1}, \ldots, x_{n}\right) \sim \Gamma\left(\alpha_{\text {shape }}, \beta\right)$, where the gamma distribution is defined as having the probability density function

$$
f\left(\alpha_{\text {shape }}, \beta\right)=\frac{\beta^{\alpha_{\text {shape }}}}{\Gamma\left(\alpha_{\text {shape }}\right)} x^{\alpha_{\text {shape }}-1} e^{-\beta x},
$$

where $\Gamma$ is the gamma function. This simulation is performed with sample size $n=1000$ on each gamma distribution with various values for shape and rate. For accuracy, the mean of the Type I Errors from 10,000 simulations was taken as the estimate for the Type I Error. 
The simulation was performed using the $\mathbf{R}$ statistical programming environment. We generated random samples from the gamma distribution in $\mathbf{R}$ using the rgamma() function and calculated its median using the qgamma() function. On each sample, the Wilcoxon Signed-Rank Test was used to test the sample median against the true median of the gamma distribution. We tested the null hypothesis that the sample median does not differ from the true median with the alternative hypothesis that the medians were different. To summarize,

$$
\begin{aligned}
& H_{0}: \operatorname{median}(\boldsymbol{x})=\operatorname{median}\left(\Gamma\left(\alpha_{\text {shape }}, \beta\right)\right), \\
& H_{A}: \operatorname{median}(\boldsymbol{x}) \neq \operatorname{median}\left(\Gamma\left(\alpha_{\text {shape }}, \beta\right)\right) .
\end{aligned}
$$

The Type I Error rate was the percentage of tests which rejected the null hypothesis. We performed the simulation using a claimed significance level $\alpha=0.01$. However, with a skewed distribution, such as the gamma function, we suspected that the Wilcoxon test will have a true Type I Error rate greater than the claimed 0.01. If the calculated Type I Error rate is less than our claimed $\alpha=0.01$, then this would imply that the Wilcoxon Signed-Rank test is conservative for postively skewed data and therefore inefficient when applied to skewed distributions. If the Type I Error rate is greater than the claimed $\alpha=0.01$, this would imply that the outcome of the Wilcoxon test is adversely affected by the lack of symmetry. In this case, we may find that the Wilcoxon Signed-Rank test may not be the most appropriate test to use to assess the status of the stations. Results from this study are given in Section 3.2.

\subsection{Rankings of Salinity Regimes}

In addition to classifying the stations' performance, we used the Tukey Honestly Significant Difference (HSD) test to see whether the salinity content of the station indirectly affects the station's performance. The Tukey HSD test is implemented by dividing all stations into salinity regimes and calculating the mean value of the percent failure (in terms of a particular parameter) within each salinity regime. The mean percent failure of each regime is then compared to all the others to test for significant differences between regimes. This comparison is based on the studentized range distribution. Significant differences between regimes indicate that salinity content significantly impacts stations' performance. The Tukey HSD test is conducted under the assumption that all observations are independent with equal variance. Classifications of each station's salinity regime was provided by DNR.

To implement the Tukey HSD, we paired each station's percent failure with its corresponding salinity regime. Once these two were paired, we fit the ANOVA model using the aov function in $\mathbf{R}$ with the percent failures as the response variables and salinity regimes as the explanatory variables. After fitting the ANOVA model, we used the TukeyHSD function in $\mathbf{R}$.

\subsection{Rankings of Stations}

In addition to analyzing the statuses of the stations, we ranked the stations' performance. The result of the ranking techniques presents a set of stations that are tied in performance, 
Table 2.1: A summary of ranking techniques used.

\begin{tabular}{|l|l|}
\hline Method & Description \\
\hline Tukey & $\begin{array}{l}\text { Performs variance transform on the data; obtains the q statistic in } \\
\text { the studentized range distribution }\end{array}$ \\
\hline Bonferroni & $\begin{array}{l}\text { Tests each of the }\left(\begin{array}{c}n \\
2\end{array}\right) \text { hypotheses at a statistical significance level of } \\
\frac{\alpha}{\left(\begin{array}{c}n \\
2\end{array}\right)}, \text { where } n \text { is the number of stations }\end{array}$ \\
\hline $\begin{array}{l}\text { Benjamini- } \\
\text { Hochberg }\end{array}$ & $\begin{array}{l}\text { For a given } \alpha, \text { finds the largest } k \text { such that } P_{(k)} \leq \frac{k}{m} \alpha, \text { where } m \text { is } \\
\text { the number of statistical tests }\end{array}$ \\
\hline $\begin{array}{l}\text { Bayesian } \\
\text { Ranking }\end{array}$ & $\begin{array}{l}\text { Transforms an assumed prior distribution to a posterior distribu- } \\
\text { tion; parameter estimates are then obtained from the posterior to } \\
\text { rank the stations }\end{array}$ \\
\hline
\end{tabular}

thus giving groupings of stations that are linked by their similarities. To rank the stations, one must compare each station to all other stations and thus perform $\left(\begin{array}{l}n \\ 2\end{array}\right)$ tests, where $n$ is the number of stations. In order to bound the Type I Error rate, we utilized multiple comparison tests. We implemented four different ranking methods: the Tukey Test, the Bonferonni Test, and the Bayesian Ranking method using the stations' percent failures, and the BenjaminiHochberg method using the stations' percent failures and means. Table 2.1 provides a brief summary of the ranking techniques, with more details in the following sub-sections.

\subsubsection{Tukey Test}

We implemented one of our ranking methods by performing a Tukey-Like Multiple Comparison Test among the stations. This testing involves a comparison of each possible pair of stations. In order to make the comparison, the percent fail first must be transformed by this function:

$$
p^{\prime}=\frac{1}{2}\left[\arcsin \sqrt{\frac{X}{n+1}}+\arcsin \sqrt{\frac{X+1}{n+1}}\right],
$$

where $X$ is the number of readings above the threshold and $n$ is the number of observations in the sample (station). Once the percent failures are transformed, we rank them based on their numerical value from smallest to largest. Then, the differences are computed between all pairs of stations: the largest and smallest, the largest and second smallest, etc. A standard error (SE) is then computed for each of the pairs using the following formula,

$$
S E=\sqrt{\frac{410.35}{n_{A}+0.5}+\frac{410.35}{n_{B}+0.5}},
$$

where $n_{A}$ is the sample size of one of the stations and $n_{B}$ is the sample size of the other station in the pair being compared. After the difference and SE are computed for the pair, they are used to compute the test statistic:

$$
q=\frac{p_{A}-p_{B}}{S E} .
$$


This 'q' statistic is then compared to a $q_{0.01}$ critical value, which comes from the q-distribution attributed to the well-known statistician John Tukey, with $\alpha=0.01$, degrees of freedom, $v$, equal to $\infty$ and $k=$ the number of groups (in this case $\left(\begin{array}{c}38 \\ 2\end{array}\right)$ ) given in Table B.5 of [10]. If the 'q' statistic $>q_{0.01}$ critical value, then we reject $H_{0}$, which assumed the stations were not equal, and conclude the stations are the same; otherwise, we fail to reject $H_{0}$ and look to the original percent failure values to see which station is faring worse. A ranking is determined by ordering the stations by the number of times a given station was declared as faring better/worse in the pairwise comparisons.

\subsubsection{Benjamini-Hochberg Method}

A more recently developed method of multiple comparisons is the Benjamini-Hochberg method. It is based on the idea of controlling the overall False Discovery Rate (FDR) as it it directly related to the expected proportion of falsely rejected hypotheses [2]. In this task, we have $\left(\begin{array}{c}38 \\ 2\end{array}\right)$ stations. Thus, letting $\alpha=0.01$, the target is to reject no more than $1 \%$ of all tested hypotheses under the assumption that all compared pairs are indeed equal. The implementation of Benjamini-Hochberg method is as follows [7]:

1. Sort the P-values $P_{(1)} \ldots P_{(m)}$ where $m$ is the number of tests

2. Find the largest $k$ such that $P_{(k)} \leq \frac{k}{m} \alpha$

3. Reject $P_{(1)} \ldots P_{(k)}$.

For pairs of stations that are found significant, the winner for the test is the station with the lower percent fail, or the mean corresponding to the 'healthier' value. This process is repeated, keeping track of each station's number of wins. The stations are then listed from most to least wins, creating a rank from best to worst condition.

\subsubsection{Bayesian Method}

Our analysis also included ranking the stations using a Bayesian ranking method. It estimates the ranks of certain unknown distribution parameters by ranking corresponding sample estimates. We model the distribution of the sample estimates for each station, $x_{i}$, by

$$
x_{i} \mid \boldsymbol{\theta} \stackrel{\text { ind }}{\sim} N\left(\theta_{i}, \sigma_{i}^{2}\right), \quad i=1, \ldots, k
$$

where $\boldsymbol{\theta}=\left(\theta_{1}, \ldots, \theta_{k}\right)$ is the vector of unknown quantities (the true percent failures). We can assume normality since the percent of failures are usually computed from a large sample. The Bayesian ranking procedure is based on the computation of posterior probabilities for all possible rankings. It determines the rank of $\theta_{i}$ by ordering the sample estimates and associating each $x_{i}$ with a corresponding rank $\widehat{r}_{i}$.

This implementation is based on simulating the posterior distribution and $n$ corresponds to the simulation sample size which is set to a large number such as 1000. To implement this method, let $\boldsymbol{S}$ be an $n \times 38$ matrix where columns correspond to 38 stations. Let $r=$ 1. For each $\theta_{i}$ in $\boldsymbol{S}$, where $i \in\{1, \ldots, 38\}$, compute the posterior probability that $\theta_{i}$ is rank $r$. To compute the posterior probability, we find the maximum element in each row and set 
it equal to 1 while all other elements in the row are set to 0 , and then compute the column sums. Once the column sums are obtained, we divide each sum by the total number of rows in $\boldsymbol{S}$. Let $\theta_{j}$ represent the station with the highest probability and associate the rank, $r$, with $\theta_{j}$. Then eliminate that column from matrix $\boldsymbol{S}$ so that $\boldsymbol{S}$ is now an $n \times(38-r)$ matrix. Continue this process, incrementing $r$, until all the stations are ranked. For more on this method and other Bayesian ranking systems, please see [1].

\section{Results}

\subsection{Stations' Statuses}

A table of our results from the Wilcoxon Signed-Rank Test can be found in Table 3.1. Each row represents a station. They are listed in alphabetical order. The columns display the stations' statuses as assigned by the Wilcoxon Test for dissolved oxygen concentration at both the $3 \mathrm{mg} / \mathrm{l}$ and $5 \mathrm{mg} / \mathrm{l}$ threshold, turbidity, chlorophyll concentration, and $\mathrm{pH}$.

According to the results of the Wilcoxon Signed-Rank Tests run on the continuous monitoring stations' data for the summer of 2011, most stations are classified as exhibiting turbidity levels significantly above the threshold level, and all but the Bishopville station, Little Monie Creek station and the stations located at the bottom of Goose and Mansonville received a 'good' status for dissolved oxygen using the $5 \mathrm{mg} / \mathrm{l}$ threshold. When the more critical dissolved oxygen concentration threshold of $3 \mathrm{mg} / \mathrm{l}$ is used, only the Bishopville station's and Little Monie Creek station's status raised from 'bad' to 'good.' This suggests that the Bishopville station and Little Monie Creek station, while not as healthy as the rest of the bay, may not be in as critical condition as the two bottom stations whose statuses remain 'bad' regardless of which dissolved oxygen threshold is used. DNR mentions that low dissolved oxygen readings during the summer months are most prominent in measurements taken from the bottom stations due to decomposing algae that has sunken and the lack of mixing between surface and bottom waters [3]. These explanations support our conclusions that two of the bottom stations are faring the worst.

The statuses for turbidity are largely 'bad' in that many stations fell above the benchmark level. On the other hand, the station statuses for chlorophyll faired quite well. This indicates that the algee blooms may have been a less of a concern during the summer of 2011 than dissolved oxygen or turbidity. Unlike turbidity, the statuses in pH are mostly 'good.' The exceptions are the Mataponi and Little Monie Creek stations which both received classifications of 'bad.' This shows that most of the stations fell within the benchmark range for $\mathrm{pH}$. Some possible reasons for the 'bad' status could be because of an algae bloom or low salinity. Overall, in terms of $\mathrm{pH}$, the stations performed well. As our future research investigates into the appropriateness of the current methodology, namely the use of the Wilcoxon Signed-Rank to determine stations' statuses, we are hesitant to draw strong conclusions regarding the heath of the bay based on current statuses. The results of the methodology exploration is discussed further in Section 3.2. 
Table 3.1: Wilcoxon Signed-Ranked Test assignment of station statuses as "Good," "Borderline," or "Bad" of Dissolved oxygen (3mg), Dissolved oxygen (5mg), Chlorophyll, Turbidity, and $\mathrm{pH}$.

\begin{tabular}{|c|c|c|c|c|c|}
\hline Station Name & DO5 & DO3 & Turbidity & Chlorophyll & pH \\
\hline Annapolis & Good & Good & $\mathrm{Bad}$ & Good & Good \\
\hline Betterton & Good & Good & Bad & Good & Good \\
\hline Big Annemessex & Good & Good & Good & Good & Good \\
\hline Bishopville & Bad & Good & Bad & Bad & Good \\
\hline Budds Landing & Good & Good & Bad & Bad & Good \\
\hline Chesapeake Y. Club & Good & Good & Bad & Good & Good \\
\hline Corisca River & Good & Good & Bad & Border & Good \\
\hline Downs Park & Good & Good & Bad & Good & Good \\
\hline Flats & Good & Good & Bad & Good & Good \\
\hline Fort Armistead & Good & Good & Bad & Good & Good \\
\hline Fort Howard & Good & Good & Bad & Good & Good \\
\hline Fort Smallwood & Good & Good & Bad & Good & Good \\
\hline Goose (bottom) & Bad & Bad & Good & Good & Good \\
\hline Goose (surface) & Good & Good & Good & Good & Good \\
\hline Gratitude Marina & Good & Good & Bad & Good & Good \\
\hline Greys Creek & Good & Good & Bad & Good & Good \\
\hline Harness Creek (down) & Good & Good & Bad & Good & Good \\
\hline Havre de Grace & Good & Good & $\mathrm{Bad}$ & Good & Good \\
\hline Indian Head & Good & Good & Bad & Good & Good \\
\hline Iron Plot Landing & Good & Good & Bad & Good & Good \\
\hline Little Monie & Bad & Good & Good & Good & Good \\
\hline Love Point & Good & Good & Bad & Good & Good \\
\hline Manokin & Good & Good & Good & Good & Good \\
\hline Masonville (bottom) & Bad & Bad & Bad & Good & Good \\
\hline Masonville Cove & Good & Good & Bad & Good & Good \\
\hline Mataponi & Good & Good & Bad & Good & Good \\
\hline Mattawoman & Good & Good & Bad & Good & Good \\
\hline McHenry & Good & Good & Good & Good & Good \\
\hline Newport Creek & Good & Good & Bad & Good & Good \\
\hline Otter Point Creek & Good & Good & Bad & Good & Good \\
\hline Possum (bottom) & Good & Good & Bad & Good & Good \\
\hline Possum Point & Good & Good & Bad & Good & Good \\
\hline Public Landing & Good & Good & Bad & Good & Good \\
\hline Railroad Bridge & Good & Good & $\mathrm{Bad}$ & Good & Good \\
\hline Sandy Point South & Good & Good & Bad & Good & Good \\
\hline Sill & Good & Good & Bad & Good & Good \\
\hline Sill (bottom) & Good & Good & Bad & Good & Good \\
\hline St. George's Creek & Good & Good & Good & Good & Good \\
\hline
\end{tabular}


Table 3.2: Type I Error of the Wilcoxon Test applied to samples drawn from the Gamma distribution with parameters $\alpha_{\text {shape }}$ and $\beta_{\text {rate }}$ using a significance level of 0.01 .

\begin{tabular}{l|cc}
\hline & \multicolumn{2}{|c}{$\beta_{\text {rate }}$} \\
& 1 & 10 \\
\hline$\alpha_{\text {shape }}=2$ & 0.8737 & 0.8692 \\
\hline$\alpha_{\text {shape }}=4$ & 0.5054 & 0.5042 \\
\hline$\alpha_{\text {shape }}=10$ & 0.1716 & 0.1701 \\
\hline$\alpha_{\text {shape }}=50$ & 0.0304 & 0.0297 \\
\hline$\alpha_{\text {shape }}=100$ & 0.0204 & 0.0205 \\
\hline
\end{tabular}

\subsection{Simulation Results}

In this section we provide the results of the simualtion conducted to investigate the sensitivity of the Wilcoxon Signed-Rank test to the non-symmetry in the data. This simualtion study is described in Section 2.2. Tables 3.2 and 3.4 show the results of the simulation. In both of the tables, the columns represent the values used for the $\beta_{\text {rate }}$ and the rows represent a set of the values used for the $\alpha_{\text {shape }}$ in the simulation. Tables 3.3 shows the average skew of each parameter (listed in the columns) at each station (listed in the rows alphabetically). Table 3.5 shows the skew of the $\Gamma\left(\alpha_{\text {shape }}, \beta_{\text {rate }}\right)$ distribution with varying $\beta_{\text {rate }}$ (listed in the columns) and $\alpha_{\text {shape }}$ (listed in the rows) values. From Table 3.5 we can see that as the $\alpha_{\text {shape }}$ parameter increases, the skew decreases. By looking at Table 3.2 and Table 3.4 we see a similar trend with the Type I Error, that is it decreases as $\alpha_{\text {shape }}$ and $\beta_{\text {rate }}$ increase. We conclude that as the skew decreases, the Type I Error rate obtained with the Wilcoxon Signed-Rank Test also decreases. Although we see similar behavior using data with and without the log-transformation, the inflation of the Type I Error is less severe with the transformation.

This gives strong evidence that the use of the Wilcoxon Signed-Rank test on the logtransformed data over the raw data is more appropriate for the highly-skewed distributions we see in the data. Comparing the skew values for the gamma distributions found in Table 3.5 to the skew values of our station data found in Table 3.3 we see that dissolved oxygen's and pH's positive skew values are in the range of the gamma distributions' skew. For turbidity and chlorophyll, we see even larger skew values than those covered with our gamma distributions. Even with the lower skew values, we see in Table 3.2 that the Wilcoxon Test still yields a Type I Error rate much larger than our claimed significance level of 0.01. The Type I Error continues to inflate with larger skew values. Notice the simulation results indicate that the log-transformation does not significantly help reduce the Type I Error for the Wilcoxon Signed-Rank Test for data with this large amount of skew. These results show that the Wilcoxon Signed-Rank Test may not be applicable to the data obtained by continuous monitoring stations. 
Table 3.3: Average skew values for each station's data for dissolved oxygen, turbidity, chlorophyll and pH. Stations are listed alphabetically.

\begin{tabular}{l|cccc}
\hline Station Name & DO & Turbidity & Chlorophyll & pH \\
\hline Annapolis & 0.8600 & 3.5520 & 5.1955 & 0.1123 \\
Betterton & 0.7221 & 3.9284 & 4.0422 & 0.6824 \\
Big Annemessex & -0.0837 & 4.7184 & 2.4859 & 0.2181 \\
Bishopville & 0.6247 & 1.5330 & 3.5572 & 0.5359 \\
Budds Landing & 0.0033 & 22.896 & 0.8347 & -0.8338 \\
Chesapeake Y. Club & 0.7433 & 2.0293 & 2.6650 & 0.5736 \\
Corisca River & 0.6647 & 3.6492 & 1.8978 & -0.0347 \\
Downs Park & -0.4362 & 3.7650 & 1.6356 & 0.4968 \\
Flats & 0.4660 & 5.5261 & 1.7057 & -0.1534 \\
Fort Armistead & 0.4411 & 3.2652 & 2.6704 & 0.2692 \\
Fort Howard & 0.0265 & 3.5911 & 1.6136 & 0.3341 \\
Fort Smallwood & -0.0350 & 7.0761 & 2.1032 & 0.3495 \\
Goose (bottom) & 0.9488 & 23.037 & 2.0776 & 0.5552 \\
Goose (surface) & 0.9363 & 3.6947 & 2.5232 & -0.1927 \\
Gratitude Marina & 0.3992 & 3.6118 & 1.7231 & 0.7324 \\
Greys Creek & 1.0849 & 5.4151 & 1.7777 & -0.1125 \\
Harness Creek (down) & 0.3694 & 3.3329 & 1.6014 & -0.0118 \\
Havre de Grace & 0.5920 & 5.3488 & 1.6738 & 0.9268 \\
Indian Head & 0.0680 & 4.1753 & 1.1078 & 0.0945 \\
Iron Plot Landing & 0.6860 & 3.7273 & 8.3336 & 0.01653 \\
Little Monie & 0.2843 & 2.2775 & 13.122 & 0.5784 \\
Love Point & 0.0870 & 3.6370 & 0.9614 & 0.1996 \\
Manokin & 0.0360 & 5.1246 & 4.1258 & -0.3016 \\
Masonville (bottom) & 0.8714 & 10.021 & 4.9516 & 1.4185 \\
Masonville Cove & 0.6011 & 5.5490 & 1.4686 & 0.3826 \\
Mataponi & 0.3116 & 9.2984 & 5.4602 & 0.5960 \\
Mattawoman & 0.3659 & 9.5283 & 0.3484 & -0.4789 \\
McHenry & 0.4703 & 5.2170 & 3.2518 & 0.5557 \\
Newport Creek & 0.1511 & 4.5250 & 0.5743 & -0.5666 \\
Otter Point Creek & 0.0653 & 4.4148 & 0.7785 & 0.1441 \\
Possum (bottom) & 0.4976 & 3.7311 & 1.9859 & 0.5159 \\
Possum Point & 0.8535 & 9.6415 & 1.5337 & 0.1973 \\
Public Landing & 0.0054 & 4.9307 & 0.5873 & 0.0193 \\
Railroad Bridge & 0.8822 & 7.9900 & 12.955 & 0.6746 \\
Sandy Point South & 0.2204 & 4.7515 & 1.1912 & 0.7569 \\
Sill & 0.8892 & 1.7235 & 2.3680 & 0.5063 \\
Sill (bottom) & 0.4632 & 1.1784 & 2.2671 & 0.8180 \\
St. George's Creek & -0.2798 & 3.4172 & 2.8722 & 0.0064 \\
\hline & & & &
\end{tabular}


Table 3.4: Type I Error of the Wilcoxon Test applied to the log-transform of samples drawn from the Gamma distribution with parameters $\alpha$ and $\beta$ using a significance of 0.01 .

\begin{tabular}{l|cc}
\hline & \multicolumn{2}{|c}{$\beta_{\text {rate }}$} \\
& 1 & 10 \\
\hline$\alpha_{\text {shape }}=2$ & 0.2183 & 0.2207 \\
\hline$\alpha_{\text {shape }}=4$ & 0.1003 & 0.0977 \\
\hline$\alpha_{\text {shape }}=10$ & 0.0407 & 0.0335 \\
\hline$\alpha_{\text {shape }}=50$ & 0.0131 & 0.0145 \\
\hline$\alpha_{\text {shape }}=100$ & 0.0116 & 0.0128 \\
\hline
\end{tabular}

Table 3.5: Skew values for a Gamma distributions with parameters $\alpha_{\text {shape }}$ and $\beta_{\text {rate }}$.

\begin{tabular}{l|cc}
\hline & \multicolumn{2}{|c}{$\beta_{\text {rate }}$} \\
& 1 & 10 \\
\hline$\alpha_{\text {shape }}=2$ & 1.4431 & 1.2808 \\
\hline$\alpha_{\text {shape }}=4$ & 0.8033 & 0.8793 \\
\hline$\alpha_{\text {shape }}=10$ & 0.6059 & 0.6356 \\
\hline$\alpha_{\text {shape }}=50$ & 0.2725 & 0.3453 \\
\hline$\alpha_{\text {shape }}=100$ & 0.0633 & 0.2306 \\
\hline
\end{tabular}

\subsection{Salinity Regimes}

Table 3.6 displays the p-values from the Tukey Test for the comparisons between the regimes. Noticing that all the p-values are greater then 0.01 , we fail to reject $H_{0}$ and conclude that none of the regimes are significantly different from each other. Because of this fact, the ranking methods are not applicable or significant to the salinity regimes.

Table 3.6: Comparing stations by salinity regimeTF $=$ Tidal Fresh $(0-0.5$ ppt $), \mathrm{OH}=$ Oligohaline (0.5-5 ppt), $\mathrm{MH}=$ Mesohaline (5-18 ppt) and $\mathrm{PH}=$ Polyhaline (18-30 ppt).

\begin{tabular}{l|lllll} 
p-value & Oxygen 3 & Oxygen 5 & Turbidity & Chlorophyll & pH \\
\hline OH-MH & 0.8528 & 0.6444 & 0.4824 & 0.9561 & 0.1745 \\
TF-MH & 0.7859 & 0.7499 & 0.9999 & 0.3261 & 0.7562 \\
TF-OH & 0.9992 & 0.9742 & 0.6079 & 0.4327 & 0.0818 \\
\hline
\end{tabular}




\subsection{Ranking}

Tables 3.7-3.11 show the results of our ranking methodologies. The first column shows the percent failure of the given station. The rows are ordered by ascending percent failures. Each column shows the results of the respective ranking methodology.

The Tukey Test using the transformed percent failures was conservative, meaning it assigned ties even when station performances were dissimilar. The Bonferoni ranking method produced even more conservative groupings than the Tukey Test. The Bayesian ranking method is the only method that does not readily lend itself to groupings and, as shown in the ranking tables, the Baysian ranking results are substantially different from other methods as well as the natural ordering of the observed point estimates. The method assumes the posterior probability distribution comes from a normal distribution using the sample percent failure as the mean. Since our data is skewed, this assumption is violated. Further study is needed to come up with more realistic prior distributions. Lastly, Table 3.6 gives the Benjamini-Hochberg method using the two-proportions Z-test for the percent fail values as well as the same method using the mean values. As expected, these two rankings do not coincide. The skew in the data is likely to impact the mean values. A similar pattern is observed in Tables 3.7-3.11 constructed for the other parameters, namely chlorophyll, turbidity, and $\mathrm{pH}$. For all ranking systems, we see that the depth of the gauge has a large effect on the rank of the station for the dissolved oxygen data. This is seen in stations like Goose whose surface gauge is ranked toward the top of the list while its deeper water gauge is ranked last. This suggests that when interpreting the dissolved oxygen rankings, one should take into consideration the depth of the gauge.

The meaning of these results depends on the use of the data. The Benjamini-Hochberg method is the ranking methodology most applicable when one wants the least conservative conclusions. However, if one wishes to see larger groupings to have a more general representation of the bay, either the Tukey or Bonferoni methods would be the most applicable. 
Table 3.7: Oxygen (5mg) - Ranking of continuous monitoring stations (with 1 being the best) with respect to its percent failure, the Tukey Test, the Bonferroni Test, Benjamini Hochberg Method, and the Bayesian Simple Ranking Method, respectively.

\begin{tabular}{|c|c|c|c|c|c|c|}
\hline \multirow[t]{2}{*}{ Station Name } & \multirow[t]{2}{*}{ \% Fail } & \multirow{2}{*}{$\begin{array}{l}\text { Tukey } \\
\text { \% Fail }\end{array}$} & \multirow{2}{*}{$\begin{array}{c}\text { Bonferroni } \\
\% \text { Fail }\end{array}$} & \multicolumn{2}{|c|}{ Benjamini } & \multirow{2}{*}{$\begin{array}{c}\text { Bayesian } \\
\% \text { Fail }\end{array}$} \\
\hline & & & & $\%$ Fail & Mean & \\
\hline Betterton & $0 \%$ & 1 & 1 & 1 & 4 & 16 \\
\hline Havre de Grace & $0 \%$ & 1 & 1 & 1 & 5 & 17 \\
\hline Flats & $0.01 \%$ & 1 & 1 & 3 & 2 & 18 \\
\hline Goose (surface) & $0.04 \%$ & 1 & 1 & 3 & 3 & 15 \\
\hline Big Annemessex & $1.34 \%$ & 5 & 5 & 5 & 16 & 19 \\
\hline AnnapolisCIBS & $2.23 \%$ & 6 & 6 & 6 & 6 & 12 \\
\hline Manokin & $2.62 \%$ & 6 & 6 & 6 & 9 & 14 \\
\hline Sill & $4.24 \%$ & 8 & 8 & 8 & 9 & 10 \\
\hline Budds Landing & $5.06 \%$ & 8 & 8 & 8 & 1 & 7 \\
\hline Love Point & $5.79 \%$ & 10 & 10 & 10 & 8 & 2 \\
\hline Iron Plot Head & $5.91 \%$ & 10 & 10 & 10 & 23 & 13 \\
\hline Fort Howard & $6.31 \%$ & 10 & 10 & 10 & 7 & 11 \\
\hline St. George's Creek & $7.62 \%$ & 13 & 13 & 13 & 20 & 9 \\
\hline Sandy Point South & $8.14 \%$ & 14 & 13 & 14 & 15 & 4 \\
\hline Possum Point & $11.98 \%$ & 15 & 15 & 15 & 9 & 20 \\
\hline Gratitude Marina & $12.60 \%$ & 15 & 15 & 15 & 22 & 21 \\
\hline Fort Smallwood & $15.09 \%$ & 17 & 17 & 17 & 9 & 8 \\
\hline Fort Armistead & $16.67 \%$ & 17 & 17 & 17 & 14 & 6 \\
\hline Public Landing & $18.58 \%$ & 19 & 19 & 19 & 27 & 24 \\
\hline Railroad Bridge Crossing & $19.50 \%$ & 20 & 20 & 20 & 18 & 23 \\
\hline Downs Park & $19.83 \%$ & 20 & 20 & 20 & 16 & 1 \\
\hline Mattawoman & $21.74 \%$ & 22 & 22 & 22 & 25 & 5 \\
\hline Otter Point Creek & $22.61 \%$ & 23 & 23 & 23 & 9 & 22 \\
\hline Indian Head & $23.73 \%$ & 23 & 23 & 23 & 18 & 3 \\
\hline Masonville Cove & $28.07 \%$ & 25 & 25 & 25 & 20 & 27 \\
\hline Harness Creek & $29.66 \%$ & 25 & 25 & 25 & 23 & 26 \\
\hline Sill (bottom) & $30.51 \%$ & 25 & 25 & 25 & 29 & 25 \\
\hline Corisca River & $37.03 \%$ & 28 & 28 & 28 & 26 & 29 \\
\hline Mataponi & $41.50 \%$ & 29 & 29 & 29 & 33 & 30 \\
\hline Newport Creek & $41.77 \%$ & 29 & 29 & 29 & 32 & 32 \\
\hline Chesapeake Yacht Club & $42.37 \%$ & 29 & 29 & 29 & 29 & 28 \\
\hline McHenry & $43.05 \%$ & 39 & 29 & 29 & 29 & 31 \\
\hline Greys Creek & $44.95 \%$ & 33 & 33 & 33 & 27 & 33 \\
\hline Possum (bottom) & $51.50 \%$ & 34 & 34 & 34 & 34 & 34 \\
\hline Bishopville & $55.78 \%$ & 35 & 35 & 35 & 35 & 35 \\
\hline Little Monie & $80.21 \%$ & 36 & 36 & 36 & 36 & 37 \\
\hline Masonville (bottom) & $80.41 \%$ & 36 & 36 & 36 & 37 & 36 \\
\hline Goose (bottom) & $89.75 \%$ & 38 & 38 & 38 & 38 & 38 \\
\hline
\end{tabular}


Table 3.8: Oxygen (3mg) - Ranking of continuous monitoring stations (with 1 being the best) with respect to its percent failure, the Tukey Test, the Bonferroni Test, Benjamini Hochberg Method, and the Bayesian Simple Ranking Method, respectively.

\begin{tabular}{|c|c|c|c|c|c|c|}
\hline \multirow[t]{2}{*}{ Station Name } & \multirow[t]{2}{*}{ \% Fail } & \multirow{2}{*}{$\begin{array}{l}\text { Tukey } \\
\text { \% Fail }\end{array}$} & \multirow{2}{*}{$\begin{array}{c}\text { Bonferroni } \\
\% \text { Fail }\end{array}$} & \multicolumn{2}{|c|}{ Benjamini } & \multirow{2}{*}{$\begin{array}{c}\text { Bayesian } \\
\% \text { Fail }\end{array}$} \\
\hline & & & & $\%$ Fail & Mean & \\
\hline Betterton & $0 \%$ & 1 & 1 & 1 & 4 & 19 \\
\hline Big Annemessex & $0 \%$ & 1 & 1 & 1 & 16 & 21 \\
\hline Flats & $0 \%$ & 1 & 1 & 1 & 2 & 22 \\
\hline Goose (surface) & $0 \%$ & 1 & 1 & 1 & 3 & 23 \\
\hline Havre de Grace & $0 \%$ & 1 & 1 & 1 & 5 & 24 \\
\hline Iron Plot Head & $0 \%$ & 1 & 1 & 1 & 23 & 25 \\
\hline Manokin & $0 \%$ & 1 & 1 & 1 & 9 & 26 \\
\hline Possum Point & $0 \%$ & 1 & 1 & 1 & 9 & 27 \\
\hline Railroad Bridge Crossing & $0 \%$ & 1 & 1 & 1 & 18 & 28 \\
\hline Sill & $0.06 \%$ & 1 & 1 & 10 & 9 & 29 \\
\hline AnnapolisCIBS & $0.10 \%$ & 1 & 1 & 10 & 6 & 20 \\
\hline Budds Landing & $0.14 \%$ & 12 & 1 & 10 & 1 & 17 \\
\hline Gratitude Marina & $0.17 \%$ & 12 & 1 & 10 & 22 & 30 \\
\hline St. George's Creek & $0.31 \%$ & 14 & 1 & 14 & 20 & 18 \\
\hline Public Landing & $0.37 \%$ & 14 & 1 & 15 & 27 & 16 \\
\hline Fort Armistead & $0.58 \%$ & 16 & 16 & 16 & 14 & 15 \\
\hline Indian Head & $0.78 \%$ & 17 & 17 & 17 & 18 & 13 \\
\hline Fort Howard & $0.86 \%$ & 18 & 17 & 17 & 7 & 14 \\
\hline Sandy Point South & $1.05 \%$ & 18 & 19 & 19 & 15 & 8 \\
\hline Love Point & $1.09 \%$ & 18 & 19 & 19 & 8 & 7 \\
\hline Fort Smallwood & $2.10 \%$ & 21 & 21 & 21 & 9 & 9 \\
\hline Mattawoman & $3.09 \%$ & 21 & 21 & 22 & 25 & 4 \\
\hline Sill (bottom) & $3.30 \%$ & 22 & 23 & 22 & 29 & 5 \\
\hline Possum (bottom) & $5.26 \%$ & 24 & 24 & 24 & 34 & 1 \\
\hline Otter Point Creek & $5.54 \%$ & 24 & 24 & 24 & 9 & 12 \\
\hline Corisca River & $8.09 \%$ & 26 & 26 & 26 & 26 & 3 \\
\hline Masonville Cove & $8.52 \%$ & 26 & 26 & 26 & 20 & 31 \\
\hline Harness Creek & $8.61 \%$ & 26 & 26 & 26 & 23 & 11 \\
\hline Downs Park & $8.91 \%$ & 26 & 26 & 26 & 16 & 2 \\
\hline Newport Creek & $10.22 \%$ & 30 & 30 & 30 & 32 & 32 \\
\hline Chesapeake Yacht Club & $10.73 \%$ & 31 & 31 & 30 & 29 & 10 \\
\hline McHenry & $13.33 \%$ & 32 & 32 & 32 & 29 & 6 \\
\hline Greys Creek & $18.04 \%$ & 33 & 33 & 33 & 27 & 34 \\
\hline Mataponi & $19.06 \%$ & 33 & 33 & 33 & 33 & 33 \\
\hline Bishopville & $26.41 \%$ & 35 & 35 & 35 & 35 & 35 \\
\hline Little Monie & $27.86 \%$ & 35 & 35 & 35 & 36 & 36 \\
\hline Masonville (bottom) & $54.87 \%$ & 37 & 37 & 37 & 37 & 37 \\
\hline Goose (bottom) & $72.00 \%$ & 38 & 38 & 38 & 38 & 38 \\
\hline
\end{tabular}


Table 3.9: Turbidity — Ranking of continuous monitoring stations (with 1 being the best) with respect to its percent failure, the Tukey Test, the Bonferroni Test, Benjamini Hochberg Method, and the Bayesian Simple Ranking Method, respectively.

\begin{tabular}{|c|c|c|c|c|c|c|}
\hline \multirow[t]{2}{*}{ Station Name } & \multirow[t]{2}{*}{ \% Fail } & \multirow{2}{*}{$\begin{array}{l}\text { Tukey } \\
\text { \% Fail }\end{array}$} & \multirow{2}{*}{$\begin{array}{c}\text { Bonferroni } \\
\% \text { Fail }\end{array}$} & \multicolumn{2}{|c|}{ Benjamini } & \multirow{2}{*}{$\begin{array}{c}\text { Bayesian } \\
\text { \% Fail }\end{array}$} \\
\hline & & & & $\%$ Fail & Mean & \\
\hline Gooses (surface) & $20.31 \%$ & 1 & 1 & 1 & 3 & 3 \\
\hline Gooses (bottom) & $23.65 \%$ & 2 & 2 & 2 & 1 & 24 \\
\hline McHenry & $27.01 \%$ & 3 & 3 & 3 & 3 & 14 \\
\hline St George's Creek & $32.30 \%$ & 4 & 4 & 4 & 6 & 1 \\
\hline Manokin & $35.40 \%$ & 5 & 5 & 5 & 5 & 32 \\
\hline Little Monie & $38.85 \%$ & 6 & 6 & 6 & 1 & 31 \\
\hline Big Annemessex & $42.28 \%$ & 7 & 7 & 7 & 8 & 29 \\
\hline Flats & $44.55 \%$ & 7 & 7 & 8 & 30 & 37 \\
\hline AnnapolisCBIBS & $45.45 \%$ & 9 & 9 & 8 & 13 & 20 \\
\hline Harness Creek & $52.95 \%$ & 10 & 10 & 10 & 8 & 23 \\
\hline Fort Smallwood & $53.29 \%$ & 10 & 10 & 10 & 12 & 15 \\
\hline Havre de Grace & $54.94 \%$ & 10 & 10 & 10 & 30 & 5 \\
\hline Bishopville & $56.94 \%$ & 13 & 13 & 13 & 6 & 19 \\
\hline Love Point & $57.14 \%$ & 13 & 13 & 13 & 19 & 17 \\
\hline Indian Head & $58.40 \%$ & 15 & 15 & 15 & 10 & 18 \\
\hline Mattawoman & $58.65 \%$ & 15 & 15 & 15 & 11 & 26 \\
\hline Masonville Cove & $59.77 \%$ & 17 & 17 & 17 & 14 & 13 \\
\hline Newport Creek & $68.24 \%$ & 18 & 18 & 18 & 18 & 33 \\
\hline Grey's Creek & $69.34 \%$ & 18 & 18 & 18 & 16 & 35 \\
\hline Mataponi & $73.33 \%$ & 20 & 20 & 20 & 34 & 28 \\
\hline Downs Park & $79.47 \%$ & 21 & 21 & 21 & 22 & 4 \\
\hline Betterton & $80.07 \%$ & 21 & 21 & 21 & 30 & 36 \\
\hline Public Landing & $80.67 \%$ & 21 & 21 & 21 & 30 & 34 \\
\hline Fort Armistead & $81.22 \%$ & 21 & 21 & 21 & 16 & 22 \\
\hline Iron Pot Landing & $82.06 \%$ & 25 & 25 & 25 & 38 & 30 \\
\hline Otter Point Creek & $86.52 \%$ & 26 & 26 & 26 & 36 & 12 \\
\hline Sill & $86.73 \%$ & 26 & 26 & 26 & 14 & 8 \\
\hline Sandy Point South & $87.85 \%$ & 26 & 26 & 26 & 22 & 2 \\
\hline Possum Point & $93.74 \%$ & 29 & 29 & 29 & 21 & 10 \\
\hline Gratitude Marina & $93.90 \%$ & 29 & 29 & 29 & 27 & 21 \\
\hline Fort Howard & $94.38 \%$ & 29 & 29 & 29 & 28 & 16 \\
\hline Chesapeake Yacht Club & $94.51 \%$ & 29 & 29 & 29 & 20 & 9 \\
\hline Masonville (bottom) & $98.22 \%$ & 33 & 33 & 33 & 37 & 25 \\
\hline Corsica River & $98.46 \%$ & 33 & 33 & 33 & 24 & 11 \\
\hline Railroad Bridge Crossing & $98.56 \%$ & 33 & 33 & 33 & 34 & 27 \\
\hline Budds Landing & $98.65 \%$ & 33 & 33 & 33 & 29 & 38 \\
\hline Sill (bottom) & $98.76 \%$ & 33 & 33 & 33 & 25 & 7 \\
\hline Possum (bottom) & $99.89 \%$ & 38 & 38 & 38 & 26 & 6 \\
\hline
\end{tabular}


Table 3.10: Chlorophyll — Ranking of continuous monitoring stations (with 1 being the best) with respect to its percent failure, the Tukey Test, the Bonferroni Test, Benjamini Hochberg Method, and the Bayesian Simple Ranking Method, respectively.

\begin{tabular}{|c|c|c|c|c|c|c|}
\hline \multirow[t]{2}{*}{ Station Name } & \multirow[t]{2}{*}{ \% Fail } & \multirow{2}{*}{$\begin{array}{l}\text { Tukey } \\
\text { \% Fail }\end{array}$} & \multirow{2}{*}{$\begin{array}{c}\text { Bonferroni } \\
\% \text { Fail }\end{array}$} & \multicolumn{2}{|c|}{ Benjamini } & \multirow{2}{*}{$\begin{array}{c}\text { Bayesian } \\
\% \text { Fail }\end{array}$} \\
\hline & & & & $\%$ Fail & Mean & \\
\hline Big Annemessex & $0 \%$ & 1 & 1 & 1 & 2 & 9 \\
\hline Mattawoman & $0 \%$ & 1 & 1 & 2 & 9 & 13 \\
\hline Public Landing & $00.01 \%$ & 1 & 1 & 2 & 11 & 23 \\
\hline Havre de Grace & $00.03 \%$ & 1 & 1 & 2 & 5 & 10 \\
\hline Betterton & $00.08 \%$ & 5 & 1 & 5 & 7 & 21 \\
\hline Manokin & $00.10 \%$ & 6 & 1 & 5 & 3 & 7 \\
\hline Flats & $00.15 \%$ & 7 & 1 & 7 & 4 & 3 \\
\hline Indian Head & $00.15 \%$ & 7 & 1 & 7 & 9 & 12 \\
\hline Love Point & $00.22 \%$ & 9 & 1 & 9 & 12 & 16 \\
\hline Otter Point Creek & $00.24 \%$ & 9 & 10 & 9 & 15 & 26 \\
\hline Iron Pot Landing & $00.59 \%$ & 11 & 11 & 11 & 1 & 25 \\
\hline Little Monie & $00.72 \%$ & 11 & 12 & 11 & 12 & 8 \\
\hline Mataponi & $01.37 \%$ & 13 & 13 & 13 & 6 & 20 \\
\hline Sandy Point South & $01.44 \%$ & 13 & 13 & 13 & 19 & 27 \\
\hline Gooses (surface) & $01.62 \%$ & 13 & 13 & 13 & 14 & 2 \\
\hline Gooses (bottom) & $02.12 \%$ & 13 & 13 & 13 & 7 & 1 \\
\hline Railroad Bridge Crossing & $02.33 \%$ & 17 & 17 & 17 & 17 & 33 \\
\hline Gratitude Marina & $03.97 \%$ & 18 & 18 & 18 & 17 & 31 \\
\hline AnnapolisCBIBS & $04.15 \%$ & 18 & 18 & 18 & 19 & 6 \\
\hline McHenry & $06.41 \%$ & 20 & 20 & 20 & 15 & 4 \\
\hline Fort Howard & $08.20 \%$ & 21 & 21 & 21 & 23 & 32 \\
\hline St. George's Creek & $08.28 \%$ & 21 & 21 & 21 & 21 & 5 \\
\hline Downs Park & $09.48 \%$ & 21 & 21 & 21 & 22 & 22 \\
\hline Masonville (bottom) & $10.28 \%$ & 24 & 24 & 24 & 26 & 34 \\
\hline Masonville Cove & $10.66 \%$ & 24 & 24 & 24 & 24 & 18 \\
\hline Fort Smallwood & $13.28 \%$ & 26 & 26 & 26 & 24 & 15 \\
\hline Sill (bottom) & $17.92 \%$ & 27 & 27 & 27 & 27 & 36 \\
\hline Fort Armistead & $18.48 \%$ & 27 & 27 & 27 & 27 & 24 \\
\hline Chesapeake Yacht Club & $20.63 \%$ & 29 & 29 & 29 & 30 & 30 \\
\hline Harness Creek & $20.96 \%$ & 30 & 30 & 29 & 29 & 14 \\
\hline Sill & $22.61 \%$ & 30 & 30 & 29 & 30 & 28 \\
\hline Possum (bottom) & $26.45 \%$ & 32 & 32 & 32 & 30 & 38 \\
\hline Possum Point & $38.02 \%$ & 33 & 33 & 33 & 33 & 29 \\
\hline Grey's Creek & $40.99 \%$ & 34 & 34 & 34 & 35 & 19 \\
\hline Corsica River & $42.99 \%$ & 34 & 34 & 34 & 37 & 35 \\
\hline Newport Creek & $46.31 \%$ & 36 & 36 & 36 & 33 & 17 \\
\hline Budds Landing & $50.19 \%$ & 37 & 37 & 37 & 36 & 37 \\
\hline Bishopville & $77.97 \%$ & 38 & 38 & 38 & 38 & 11 \\
\hline
\end{tabular}


Table 3.11: $\mathbf{p H}$ - Ranking of continuous monitoring stations (with 1 being the best) with respect to its percent failure, the Tukey Test, the Bonferroni Test, Benjamini Hochberg Method, and the Bayesian Simple Ranking Method, respectively.

\begin{tabular}{|c|c|c|c|c|c|c|}
\hline \multirow[t]{2}{*}{ Station Name } & \multirow[t]{2}{*}{ \% Fail } & \multirow{2}{*}{$\begin{array}{l}\text { Tukey } \\
\text { \% Fail }\end{array}$} & \multirow{2}{*}{$\begin{array}{c}\text { Bonferroni } \\
\% \text { Fail }\end{array}$} & \multicolumn{2}{|c|}{ Benjamini } & \multirow{2}{*}{$\begin{array}{c}\text { Bayesian } \\
\% \text { Fail }\end{array}$} \\
\hline & & & & $\%$ Fail & Mean & \\
\hline Big Annemessex & $0 \%$ & 1 & 1 & 1 & 18 & 29 \\
\hline Iron Pot Landing & $0 \%$ & 1 & 1 & 1 & 4 & 30 \\
\hline Little Monie & $0 \%$ & 1 & 1 & 1 & 2 & 31 \\
\hline Manokin & $0 \%$ & 1 & 1 & 1 & 14 & 32 \\
\hline Mataponi & $0 \%$ & 1 & 1 & 1 & 1 & 28 \\
\hline Newport Creek & $0 \%$ & 1 & 1 & 1 & 7 & 33 \\
\hline Public Landing & $0 \%$ & 1 & 1 & 1 & 12 & 34 \\
\hline Railroad Bridge Crossing & $00.05 \%$ & 1 & 1 & 8 & 3 & 27 \\
\hline Gooses (bottom) & $00.41 \%$ & 9 & 9 & 9 & 9 & 24 \\
\hline Grey's Creek & $00.43 \%$ & 9 & 10 & 9 & 8 & 35 \\
\hline Masonville (bottom) & $02.63 \%$ & 11 & 11 & 11 & 6 & 25 \\
\hline Bishopville & $04.62 \%$ & 12 & 12 & 12 & 10 & 19 \\
\hline Havre de Grace & $05.84 \%$ & 13 & 13 & 13 & 11 & 5 \\
\hline Indian Head & $07.99 \%$ & 14 & 14 & 14 & 5 & 18 \\
\hline Betterton & $08.15 \%$ & 14 & 14 & 14 & 12 & 36 \\
\hline Gratitude Marina & $08.39 \%$ & 14 & 14 & 14 & 20 & 21 \\
\hline Love Point & $09.44 \%$ & 17 & 17 & 17 & 26 & 17 \\
\hline Sandy Point South & $09.64 \%$ & 18 & 17 & 18 & 21 & 2 \\
\hline Mattawoman & $13.53 \%$ & 19 & 19 & 19 & 14 & 26 \\
\hline McHenry & $13.88 \%$ & 19 & 19 & 19 & 17 & 14 \\
\hline AnnapolisCBIBS & $14.45 \%$ & 19 & 19 & 19 & 28 & 20 \\
\hline Possum (bottom) & $17.49 \%$ & 22 & 22 & 22 & 19 & 6 \\
\hline Sill (bottom) & $18.39 \%$ & 22 & 22 & 22 & 24 & 7 \\
\hline Downs Park & $19.40 \%$ & 22 & 22 & 24 & 26 & 4 \\
\hline Fort Armistead & $20.26 \%$ & 25 & 25 & 24 & 29 & 22 \\
\hline Masonville Cove & $20.61 \%$ & 26 & 26 & 26 & 21 & 13 \\
\hline Corsica River & $20.92 \%$ & 26 & 26 & 26 & 24 & 11 \\
\hline Sill & $24.92 \%$ & 28 & 28 & 28 & 30 & 8 \\
\hline Fort Smallwood & $25.13 \%$ & 28 & 28 & 28 & 32 & 15 \\
\hline Chesapeake Yacht Club & $26.21 \%$ & 28 & 28 & 28 & 21 & 9 \\
\hline Harness Creek & $26.36 \%$ & 28 & 28 & 28 & 30 & 23 \\
\hline Gooses (surface) & $26.82 \%$ & 28 & 28 & 28 & 35 & 3 \\
\hline St George's Creek & $28.26 \%$ & 33 & 33 & 33 & 35 & 1 \\
\hline Fort Howard & $28.37 \%$ & 33 & 33 & 33 & 32 & 16 \\
\hline Possum Point & $30.89 \%$ & 35 & 35 & 35 & 32 & 10 \\
\hline Otter Point Creek & $31.07 \%$ & 35 & 36 & 35 & 16 & 12 \\
\hline Flats & $48.94 \%$ & 37 & 37 & 37 & 38 & 37 \\
\hline Budds Landing & $59.38 \%$ & 38 & 38 & 38 & 37 & 38 \\
\hline
\end{tabular}




\section{Limitations of Project}

Our results only apply for the tests we conducted on shallow-water stations and may not apply to the Chesapeake Bay as a whole. For further inquiry, see www. eyesonthebay .net.

\section{Acknowledgments}

We would like to thank our client, Dr. Brian R. Smith from Maryland's Department of Natural Resources, for posing the project and his mentorship; our faculty mentors, Dr. Nagaraj K. Neerchal and Dr. Matthias K. Gobbert, for their guidance, assistance, and feedback; and our graduate assistant, Sai K. Popuri, for his helpful input and advice. For more information reguarding the full scope of the project, please see our technical report [6].

These results were obtained as part of the REU Site: Interdisciplinary Program in High Performance Computing (www.umbc.edu/hpcreu) in the Department of Mathematics and Statistics at the University of Maryland, Baltimore County (UMBC) in Summer 2012. This program is funded jointly by the National Science Foundation and the National Security Agency (NSF grant no. DMS-1156976), with additional support from UMBC, the Department of Mathematics and Statistics, the Center for Interdisciplinary Research and Consulting (CIRC), and the UMBC High Performance Computing Facility (HPCF).

\section{References}

[1] Samantha Allen, Dorthy Kirlew, Neil Obetz, Derek Wade, April Albertine, Nagaraj K. Neerchal, and Martin Klein. Assesment of simple and alternative bayesian ranking methods utilizing parallel computing. Technical Report HPCF-2011-11, UMBC High Performance Computing Facility, University of Maryland, Baltimore County, 2011.

[2] Yoav Benjamini and Yosef Hochberg. Controlling the false discovery rate: A practical and powerful approach to multiple testing. Journal of the Royal Statistical Society. Series B (Methodological), 57:289300, 1995.

[3] Maryland's Department of Natural Resources: Eyes on the Bay. www. eyesonthebay . net.

[4] Elizabeth Ebersole, Mike Lane, Marcia Olson, Elgin Perry, and Bill Romano. Assumptions and Procedures for Calculating Water Quality Status and Trends in Tidal Waters of the Chesapeake Bay and its Tributaries: A cumulative history. Tidal Monitoring and Analysis Workgroup, 2002.

[5] The value of wetlands. U.S. Fish and Wildlife Service Website, www.fws .gov.

[6] Rosemary K. Le, Christopher V. Rackauckas, Anne S. Ross, Nehemias Ulloa, Sai K. Popuri, Nagaraj K. Neerchal, and Brian R. Smith. Water quality monitoring of Maryland's tidal waterways. Technical Report HPCF-2012-12, UMBC High Performance Computing Facility, University of Maryland, Baltimore County, 2012.

[7] The false discovery rate (FDR) procedure. NAEP Technical Documentation Website, November 2009. Accessed in August, 2012.

[8] Chesapeake Bay. National Wildlife Federation Website, www.nwf.org.

[9] Brian R. Smith. Email correspondence, July 2012.

[10] Jerrold H. Zar. Biostatistical Analysis. Pearson Prentice Hall, fifth edition, 2010. 